\title{
Scientific Management of Knowledge as a Resource in the Learning System of Security and Defence
}

\author{
Stojko Stojkov \\ Vasil Levski National Military University, Bulgaria \\ Sevdalina Dimitrova \\ Vasil Levski National Military University, Bulgaria \\ Rumen Marinov \\ Vasil Levski National Military University, Bulgaria
}

\begin{abstract}
The need to introduce scientific management and change management, while respecting the requirements for efficiency and transparency in the security industry, requires the corresponding responsibility to the obligations and adaptability to the changes in the security environment, to the risks and challenges. Building knowledge-based security is a demanding task but also a challenge for teams in science education organizations in the security sector. The goal of scientific research is to provide, based on the scientific, systematic and managerial approaches, a relatively complete theoretical concept of the need for strategic knowledge management in the security system that will allow our country to be a source rather than a consumer of security in the modern European family and the Euro-Atlantic community. Modern knowledge management in the security system implies creating prerequisites for its successful management rather than administering the limited resources in the system.
\end{abstract}

Keywords: security and defence, strategic management, security and defence management, knowledge management

JEL classification: D83, H56

\section{Introduction}

In recent decades, knowledge, as a product of natural, innovative solutions characteristic of all living natural systems, has acquired the status of a privileged socio-economic category of management. Knowledge Management is a highly technologically advanced and complex platform that responds to advanced trends such as interactive learning, communication content management, knowledge platforms, expert systems, data extracting and visualization (Piccoli et al., 2000; Tippins et al., 2003). For organizations with a future in the security system, knowledge is an extremely valuable intangible asset and without its proper management, it will be increasingly difficult for them to survive in the extremely dynamically changing environment (Wong et al., 2004). Choosing a winning knowledge strategy for the organization depends on the strategic pressure and on the value it strives for, on the threats, it faces in its activities and on the opportunities, it wants to make use of through it.

In scientific theory and the good practices in finding reasoned answers to the increasingly difficult problem of finding the balance between rising demands, limited and diminishing resources and necessary capabilities in the security sector of society, 
the approach to national security as a social good and public need in the 21 st century stands out (Prodanov, 2001). The need to introduce scientific management and change management, while respecting the requirements for efficiency and transparency in the security industry, requires the corresponding responsibility to the obligations and adaptability to the changes, risks and challenges in the security environment. Building knowledge-based security is a demanding task but also a challenge for teams in scientific and educational organizations in the security sector. The strategic management of knowledge in them is the paradigm that allows them through the power of scientific knowledge to change its role in creating a future integrated national security sector contributing to the county's "intelligent security".

The topicality of the discussed scientific issue from theoretical and applied point of view is dictated by the internal logic of security development as a scientific field and by the process of knowledge in it as a scientific direction. It is a scientific direction where the achievements of scientific and educational organizations in the security sector will allow them to identify the steps towards turning their scientific knowledge into much needed expertise for ensuring sustainable development and competitiveness when addressing the societal challenges that worry European citizens. In this respect, the challenges and problems are familiar and at the same time unknown, with the scope for scientific research and practical interpretations corresponding to the dynamics of the changes in the new security environment.

All this allows for presenting a relatively complete theoretical concept of the identified scientific problem of the need for strategic management of knowledge in the security system, which will allow our country to be a source rather than a consumer of security in the modern European family and the Euro-Atlantic community that defines the purpose of our research. The purpose thus formulated is a complex function of the desired result, which should satisfy the requirements of complexity, system, coherence and reality in the research, in obtaining specific quantitative and qualitative performance characteristics.

The requirement for original interpretation of cognitive problems in the conceptual framework of a completed theory through the scientific approach and the achievement of the goal is sought by the deduced dependence between public management and science as an imperative for successful social development in the "Europe of Knowledge"; the established place of science and the scientific method in the knowledge management in the learning security and defense system; the analysis of national security as a public good and necessity in the modern public organization of state life; the demonstrated institutional basis and structure of the future integrated security sector through strategic knowledge management, creating resource and capital rather than spending in the economy of competing knowledge. This is in support of the Bologna Declaration of 19 June 1999, which is one of the first papers in which there is no sharp discrimination between academic and vocational education - hence the need to work to towards enhancing the opportunities for lifelong learning. Moreover, the knowledge management in the scientific-educational organizations of the security system has to make any effort to develop the young scientists as creative and productive ones, because the one thinks and dreams small moves forward with tiny steps. The knowledge management programs in the security education organizations are called upon to control the process of creating or identifying, accumulating and applying knowledge or the scientific and intellectual capital in the organization, to lead to shared intelligence, opportunities for better performance and competitive advantage in transferring new knowledge at high levels of innovation in a highly specific area of higher education Security and Defence. Following the example of Focus on higher education in 
Europe 2010: the impact of the bologna process (Education, Audiovisual and Culture Executive Agency, 2010).

\section{Methodology}

Knowledge management encompasses various management tools related to the concepts of managing the intellectual capital of the organization and the idea of a learning (not self-learning) organization. It covers a wide range of practices applied by the organization to identify, create, present, acquire and disseminate knowledge, focus efforts on organizational goals and create prerequisites for increasing competitive advantages, innovations, shared lessons and continuous improvement of the organization. This is possible provided there is retention and creative development of the intellectual capital of the organization under the favourable conditions created by the system for successful adaptation to the aggressively changing external environment and markets.

In the absence of unity between teaching and research, the implementation of administrative measures does not lead to the institutional strengthening of the relevant structures, but only gives a pompous character to the learning process that takes place in them (Raymond et al., 1978). An impartial analysis, unfortunately, can hardly be conducted, but we can immediately notice that the process of acquiring the educational and scientific degree "doctor" has to be brought in line with its name - "educational" and "scientific" - because in many places the educational part is underestimated. It is left to the discretion of the individual main units where the students, unfortunately for them, are also our subordinates.

\section{Results}

The analysis of the training that is organized for PhD students, post-graduate students, and trainees in our scientific-educational organization shows in detail that the knowledge accumulated in this process is not shared in perhaps the most effective way and does not create conditions for the development of students' scientific thinking. The post-doctoral period in the work of young scientists still does not allow the realization of the acquired scientific knowledge. Transformation processes in the security system require firm knowledge, development and use of their own capabilities as part of the overall realization of capabilities in specific conditions.

Educational organizations in the security system which have scientific institutes in their structure can successfully combine education with research because, unlike the schools where knowledge is transferred, they will create not just knowledge, but modern knowledge - a modern product, attractive for young scientists and researchers.

Having the foundation that allows you to develop and perfect your potential is the advantage that the science and education institutions in the military education system (MES) of the Ministry of Defence avail of and of which not everyone can boast. Few are the disciplines and majors that can highlight opportunities, give knowledge embodied in a blend of past, present and future, that make you not just learn something, but teach you how to think properly at any time and in any situation, while bearing responsibility, through our decision, for the most valuable good entrusted to us - human life.

Retaining the current knowledge management principles doom research activity in the system to extinction. Lifelong learning is an inevitable reality and a strategic prospect of development rather than survival, a prospect, which is only possible for science, and education organizations that have realized that knowledge is a 
mediator and an ally, not an opponent in solving the problem of achieving the next goal of the organization. The one who will survive on the market of higher education is the one who successfully manages their commodity - knowledge.

The longstanding scientific interest and professional orientation towards the studied subject, the wisdom in the lessons learned from the past, the growing dynamics of the problematic present and the hope for predictability in the future of the security sector allow us to draw the following conclusions:

0 it is necessary to enrich the existing knowledge and skills in the theory and practice of the role of strategic security management as an effective factor in the formation of an adequate and efficient security policy;

- the results of the conducted research have undoubtedly demonstrated that the interaction between public governance (both as theory and practice) and the scientific management of security resources is a leading imperative for successful public development in the scientific and management sphere of the security system;

- the national security of modern society is a good and a necessity, where security should be regarded as an economic activity. The approaches to its development, decision-making and implementation of management decisions are not different from business organizations, as the effects of the transformation of the resources invested in security have the ultimate goal of achieving the objectives set by the security system;

- on the basis of a complex approach and through the generating of new knowledge and skills to increase the effectiveness of the transformation phase in the management of knowledge resources in the security system, the existing theoretical rationale and practical formulations can be enriched and expanded.

\section{Discussion}

Improving the National Rating Ranking of Universities established in 2010, in line with their prestige and transformation into science education, is undoubtedly a measure of quality education and would be of great importance to our society, institutions, students, industry and other users of highly qualified personnel (e.g. Webometrics, n.a.).

Taking into account the contemporary trends in the development of science, and in particular the interdisciplinary nature of applied research, as well as the penetration of computer technologies into all other branches of science, are at the root of successful knowledge management in scientific-educational organizations in the security system. In fact, we now understand more clearly that our lives have changed, and with that - our values as well.

Modern knowledge management in the security system implies creating prerequisites for successful managing rather than commanding (administering) the scarce resources remaining in the system. We are convinced that the research, analysis, results and projections made in our present study will be used by all those interested in applying good practices and scientific management of changes in our military education system in order to resolve the issues of a security system management that is oriented towards targeted allocation of resources.

\section{Conclusion}

In order to direct the knowledge management and the practical activities of organizations towards one goal, integration between the experts teams in the 
administration of the institutions and the research potential of the academic community, which is actively involved in the search for reasonable solutions to the problems in the security system, is necessary. We need far more abilities to see the future consequences of the decisions we make today.

It is absolutely clear to us that if state scientific and educational organizations in the security system do not become a natural center for good management of modern knowledge, they will become an unnecessary burden on the national security system, and then their educational and scientific functions will be taken over by the civilian scientific-educational organizations, and the training and qualification functions - by specialized post-graduate qualification centers.

We have no claim to the universality of our research, which, for the purposes of this publication, is limited to fragmenting the conceptual framework of knowledge management in the security sector based on the scientific approach. However, we have ambitions for future research and development because we do not alter the goals we have failed to achieve in our activities so far but our future actions that will lead to accomplishing dignified tasks. In this context, our future research is geared towards the applicability of comprehensive and competence approaches to education and training in the security system. Because the scientific "front" is defeated by the weapon called knowledge and the "open market" called security, we are a good opportunity for priority investment in "knowledge".

\section{References}

1. Education, Audiovisual and Culture Executive Agency (2010) "Focus on Higher Education in Europe 2010: the Impact of the Bologna Process", available at: http://www.aic.lv/bolona/2010/Reports/Focus2010.pdf (1 February 2018)

2. Miles, R.E., Snow, C.C., Meyer, A.D. and Coleman Jr, H.J. (1978) "Organizational Strategy, Structure, and Process", The Academy of Management Review, Vol. 3, No. 3, pp. 546-562.

3. Piccoli, G., Ahmad, R., Ives, B. (2000), "Knowledge management in academia: A proposed framework" Information Technology and Management, Vol. 1, No. 4, pp. 229-245.

4. Prodanov, V. (2001), Synergic Paradigm of National Security, Scientific conference of thonal and World Economy, Economy.

5. Tippins, M. J. (2003), "Implementing knowledge management in academia: teaching the teachers", International Journal of Educational Management, Vol. 17, No. 7, pp. 339-345.

6. Webometrics (n.a). Ranking web of universities. available at: http://www.webometrics.info/en/search/Rankings/bulgaria (18 January 2017)

7. Wong, K. Y., Aspinwall, E. (2004), "Knowledge management implementation frameworks: a review", Knowledge and Process Management, Vol. 11, No.2, pp. 93104. 


\section{About the authors}

Stoyko Stoykov works as the professor Doctor of Economics at the "Vasil Levski" National Military University, in the Scientific Research and Innovation Institute. He is a professor in "Security and Defense" and a DSC in "Administration and Management". His main research interests are strategic management, security and defense management; knowledge management. The author can be contacted at stojkods@abv.bg.

Sevdalina Dimitrowa works as the professor Doctor of Economics at the "Vasil Levski" National Military University, in the Scientific Research and Innovation Institute. She is a professor DECSC in "Security and Defense" and in "Administration and Management". She is an Author of over 375 scientific publications in point. H. Large doctoral thesis, 9 monographs (3-copyright; 6-co-6- collective), 25 studios, 14 textbooks in the field of resource management for security and defense, accounting, finance, sustainable development, ecology and its economic aspects, marketing, logistics, social governance, employment, labor market and others. She is a Head of 12 PhD students, of which 10 successfully defended. Reviewer for the acquisition ONS "Doctor", a scientific degree of "Doctor of Sciences", for academic positions "professor", "associate professor" of monographs, scientific publications, textbooks and scientific projects. Chairman of the scientific juries, state examination boards, committees to conduct doctoral examinations. Member of the Standing Commission on Social and Legal Studies, security and defense policy at the National Agency for Assessment and Accreditation. Author can be contacted at sevdalinaid_bg@mail.bg.

Rumen Marinov is Associate Professor of the Faculty of "Land forces", National Military University "Vasil Levski", Department of "Military Sciences". In 2012, he defended dissertation at the Defence Colleague "G.S. Rakovski", Sofia, on "Exploring the capabilities of subdivisions in conducting combat in critical time in urban terrain". In June 2017 he was elected for Associate Professor at the NMU "Vasil Levski", Department of "Military Sciences", and in October he became Chief of the same Department. His main interests are related to asymmetric threats, urban territories and military security in the context of national security. Rumen Marinov published several scientific papers in international and national magazines and participated in many scientific international conferences in the country and abroad. The author can be contacted at marinov_r@nvu.bg. 